\title{
MODERN METHODS FOR FOOD SAFETY
}

\author{
Ruslan Omarov, Alexander Agarkov, Evgeny Rastovarov, Sergei Shlykov \\ Stavropol State Agrarian University, Russia \\ doooctor@yandex.ru, scopush@gmail.com, shlykovsn@gmail.com
}

\begin{abstract}
Over the last decade the number of toxicants increased that affect the safety of raw materials and food, simultaneously with it, the time increases and methods are complicated for their determination. The complete analysis of the quality and food safety for all normalized indicators is quite costly. In this regard, integrated quality control by biotesting is relevant. The purpose of work - experimental evaluation methods: determination of acute toxicity by the culture of ciliates Tetrahymena pyriformis for control of the safety of raw materials and food products in the process of monitoring. The objects of the study were fresh herbs (parsley, dill), wild boar, duck, beef, mincemeat (beef, pork), fish (pike). The paper presents the results of studies evaluating the methods by biotesting for control of food safety in the process of monitoring. In most cases, the correlation results showed determination of toxicity by methods to determining acute toxicity on ciliates, and also content specific anthropogenic and natural toxicants. The method for determining acute toxicity by ciliates is sufficiently rapid, does not require using of experimental animals or costly equipment and has prospects for acceleration of safety control of raw materials and food products.
\end{abstract}

Keywords: food safety, Tetrahymena pyriformis, express analysis, toxicity, ciliates.

\section{Introduction}

With global food safety testing services projected to reach nearly 20 billion USD by 2022, the food industry is met with increasing demands from both the consumer and regulatory agencies to maintain a safe food product.

Contaminants may occur in our food from various sources. They typically pose a health concern, resulting in strict regulations of their levels by national governments and internationally by the Codex Alimentarius Commission. Therefore, analysis of relevant chemical contaminants is an essential part of food safety testing programs to ensure consumer safety and compliance with regulatory limits. Modern analytical techniques can determine known chemical contaminants in complex food matrices at very low concentration levels. Moreover, they can also help discover and identify new or unexpected chemical contaminants.

Contaminants can be present in foods mainly as a result of the use of agrochemicals, such as residues of pesticides and veterinary drugs, contamination from environmental sources (water, air or soil pollution), cross-contamination or formation during food processing, migration from food packaging materials, presence or contamination by natural toxins or use of unapproved food additives and adulterants.

Guaranteeing safe food is a complex task. This is because food is increasingly being traded at global level, new ingredients and products are being developed, pathogens occur and consumers change their eating habits. Identifying and implementing adequate control measures is the only thing that stands between your food business producing safe food or not [1].

An important task of food industry is ensuring and monitoring the safety of products. The presence in food of anthropogenic and natural toxicants is the most common cause of security breaches [2]. The former includes heavy metals, dioxins, synthetic plant growth regulators, substances used in livestock: drugs (antibiotic, antiparasitic, hormonal drugs), phosphorus and chlorogenic pesticides etc [4]. The second group, toxins and metabolites of bacteria, fungi, plants [3]. Detection and identification of contaminants is not an easy task, especially if they are present at low concentration levels. It requires expertise and a good analytical strategy that is based on all gathered information about the sample and potential sources of contamination. Any clues, such as changes in smell, taste or texture, as well as a description of potential poisoning symptoms may be important in this respect. Concurrent analysis of control ("good") samples with suspect samples is often essential to find differences and eliminate potential false positives.

At the same time, research has improved analytical methods offering faster turnaround times for results with higher sensitivity for low-level contaminants and detection of contaminants in complex matrices. With increasing demands to test foods for more potential safety hazards, many companies 
look to automation. Big food producers and global food companies are trying to centralize their testing for cost savings, and this means that technology has to be set for high throughput.

There are a large number of biological models for assessment of toxicity; the most frequently used are laboratory animals and single-celled organisms [7]. Various modifications of the method of biotesting were successfully used to define many objects of food production and the environment [6]. Using Tetrahymena pyriformis (Figure 1) to determine the toxicity of food is seen as a promising way. The increasing use of Tetrahymena for both research and educational purposes has been facilitated by the ease with which it can be grown and maintained in a wide range of conditions, ranging from single cells in hanging drops to multi-liter cultures grown in large bio-reactors.

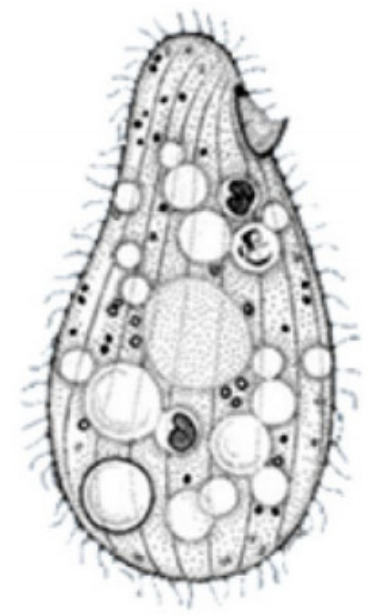

Fig. 1. Examples of morphotypes of Tetrahymena (ciliate)

The purpose of this research is the experimental evaluation methodology for determining acute toxicity for safety control of raw materials and food in the process of monitoring.

\section{Materials and methods}

The objects of the study were fresh herbs (parsley, dill), wild boar, duck, beef, mincemeat (beef, pork), fish (pike). Each sample weighed approximately 500 to $550 \mathrm{~g}$. Subsamples for enumeration of bacteria and flagellates were diluted and then stained with acridine orange prior to observation via epifluorescence microscopy on $0.22-\mu \mathrm{m}$-pore-size millipore black 25 -mm-diameter filters, similar to the methods of Hobbie et al. [8]. Other subsamples were examined by phase-contrast microscopy under an inverted microscope. All data were converted to numbers of organisms per milliliter of the drainage from produce.

The samples were washed with sterile Tris-buffered saline solution (TBSS; $2 \mathrm{mM} \mathrm{KCl,} 1 \mathrm{mM}$ $\mathrm{CaCl} 2,0.5 \mathrm{mM} \mathrm{MgCl} 2,1 \mathrm{mM}$ Tris [pH 6.8 to 7.2$]$ ) while they were still in the closed, clean plastic bags. The sample washings were then transferred aseptically into sterile petri dishes. Autoclaved wheat grains were added to the petri dishes to enrich for protozoa in the produce wash water. Enrichment would permit easier isolation because of higher concentrations of a given organism and possibly reveal the presence of more species by inducing excystment of certain cyst-forming species. The dishes were then incubated at $25^{\circ} \mathrm{C}$ for 24 to $48 \mathrm{~h}$. After incubation, the suspensions in the dishes were observed under an inverted microscope for the presence of protozoa.

The culture of ciliate Tetrahymena pyriformis were cultured in a thermostat at sterile conditions in test tubes on a nutrient medium of the following composition: bacterial peptone -20.0 ; glucose -5.0 ; sodium chloride -1.0 ; yeast extract -1.0 (concentration, $\mathrm{g} \cdot \mathrm{dm}^{-3}$ distilled water). For biotesting 3-day culture of ciliates was used. The density of suspension cells in culture was $(6-8 \times 104) \mathrm{cells} \cdot \mathrm{cm}^{-3}$. For tests 25 to $50 \mathrm{~g}$ samples were used. Liquid products were investigated in natural form or in the form of aqueous emulsion. Solid products ( $25 \mathrm{~g}$ ) were pre-crushed in a homogenizer.

For grazing experiments, 2-week-old cultures of Glaucoma sp. were used because of the slow growth of these ciliates, whereas 3-day-old cultures of C. steinii and 5-day-old cultures of two Tetrahymena species were used. Ciliates were washed with TBSS by centrifugation at $500 \times \mathrm{g}$ and 
resuspended in TBSS. Amoebae were washed from NNA plates and suspended in TBSS. The concentration of protozoa in stock suspensions was determined by differential interference contrast (DIC) microscopy. For grazing tests, 24-h-old broth cultures of S. enterica MB108, E. coli O157:H7 MB269, and L. monocytogenes RM2387 were washed twice by centrifugation and the final pellet was resuspended in TBSS. The concentration of bacteria in the stock suspension was determined by epifluorescence microscopy.

Cocultures of protozoa and bacteria were established at a ratio of bacteria to protozoa of 10,000:1. Controls consisted of suspensions of washed protozoa only. Cocultures were incubated at $25^{\circ} \mathrm{C}$ for $24 \mathrm{~h}$. All coculture experiments with bacteria and protozoa were performed twice with two replicate suspensions.

The experiment was treated as a split-plot design in time with cuts as subplots. A linear mixed model was used to estimate the variance components [5]. The analysis was carried out using the REML (restricted maximum likelihood) analysis in Genstat (14th edition;VSN International Ltd, Hemel Hempstead, UK).

\section{Results and discussion}

By using the methodology for determining acute toxicity for extraction toxic substances distilled water, physiological saline or phosphate buffer $(\mathrm{pH}$ 7.2) were used. After extraction, the homogenate was filtered through a 2-folded paper filter. If the $\mathrm{pH}$ of the investigated sample is acidic or strongly alkaline, its $\mathrm{pH}$ is adjusted to 7.0 and 7.2 by phosphate buffer. The extraction time is $15-20 \mathrm{~min}$.

The evaluation results were obtained by the results of acute toxic action tested objects on ciliates. The sample after extraction was mixed with cell culture 1:1. The method of measurement of the testresponse - visual assessment (counting) under the microscope number of test objects through certain intervals of time (15 min, $30 \mathrm{~min}, 1 \mathrm{~h}$ ) (Figure 2).

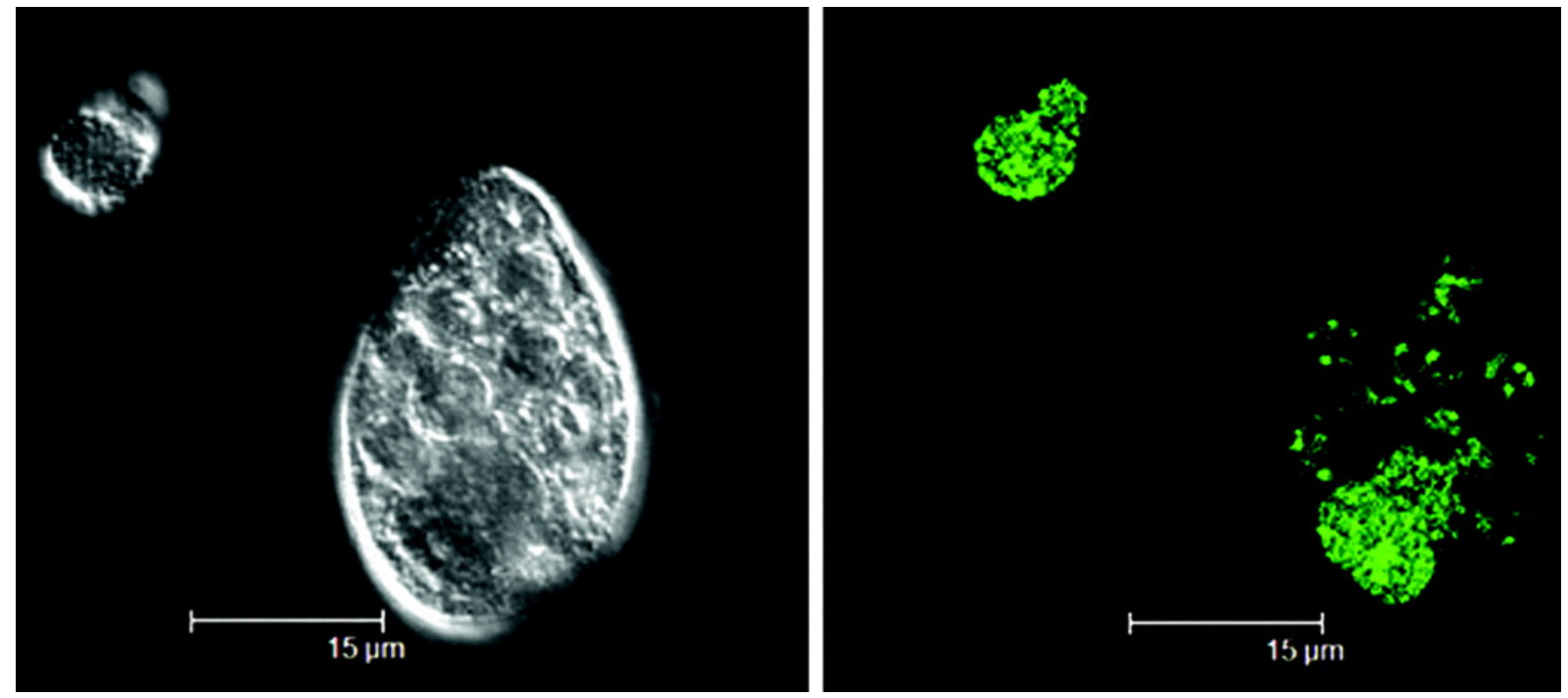

Fig. 2. Cell of Tetrahymena strain MB1125 containing E. coli 0157:H7 and expelled vesicle outside the cell. (Left) DIC image; (right) fluorescent confocal image

Protozoa increased in numbers after fed on pathogens for $24 \mathrm{~h}$. Acute toxicity - death of $100 \%$ of ciliates within $1 \mathrm{~h}$. (Table 1 ).

In the monitoring process over 1000 samples were analyzed. Of them, $0.9 \%$ showed toxic effect. The results of toxicity determination by biotesting on ciliates mostly correlated with the concentration of specific toxicants parallelly identified by other methods.

In the study of minced meat samples, in which by biotesting the reaction of Tetrahymena was observed, also the presence of Salmonella was noted. 
Results of control safety of raw materials and foodstuff

\begin{tabular}{|c|c|c|c|c|c|}
\hline \multirow{2}{*}{$\begin{array}{c}\text { Product } \\
\text { type }\end{array}$} & $\begin{array}{c}\text { Number } \\
\text { of } \\
\text { rejected } \\
\text { samples }\end{array}$ & $\begin{array}{c}\text { Acute } \\
\text { toxicity on } \\
\text { the ciliate }\end{array}$ & Microbiological & $\begin{array}{c}\text { High pressure } \\
\text { liquid } \\
\text { chromatography }\end{array}$ & Ionometric \\
\hline $\begin{array}{c}\text { Fresh herbs } \\
\text { (parsley, } \\
\text { dill) }\end{array}$ & 4 & Positive & Not identified & Not identified & $\begin{array}{c}\text { Nitrates, } \\
\text { nitrites }\end{array}$ \\
\hline Wild boar & 1 & Negative & Not identified & Hydrargyrum & $\begin{array}{c}\text { Not } \\
\text { identified }\end{array}$ \\
\hline Duck & 1 & Negative & Not identified & Plumbum & $\begin{array}{c}\text { Not } \\
\text { identified }\end{array}$ \\
\hline Beef & 1 & Negative & Not identified & Hydrargyrum & $\begin{array}{c}\text { Not } \\
\text { identified }\end{array}$ \\
\hline $\begin{array}{c}\text { Mincemeat } \\
\text { (beef, pork) }\end{array}$ & 1 & Positive & Salmonella & Not identified & $\begin{array}{c}\text { Not } \\
\text { identified }\end{array}$ \\
\hline Fish (pike) & 1 & Negative & Vibriosis & Not identified & $\begin{array}{c}\text { Not } \\
\text { identified }\end{array}$ \\
\hline
\end{tabular}

\section{Conclusions}

1. The data for determining the safety of various food products by biotesting acute toxicity on ciliate, physico-chemical and microbiological methods for detection specific man-made or natural toxicants in most cases showed a correlation of the results.

2. The method for determining acute toxicity by ciliates is sufficiently rapid, does not require to use experimental animals or costly equipment and has prospects for accelerated safety control of raw materials and food products, however, its practical implementation should be adapted for specific objects and toxicants.

\section{References}

1. Charteris W.P., Kelly P.M., Morelli L., Collins J.K. Ingredient selection criteria for probiotic microorganisms in functional dairy foods. Int. J. Dairy Technol, vol. 51, 1998,pp.123-136.

2. Devirgiliis C., Barile S., Perozzi, G. Antibiotic resistance determinants in the interplay between food and gut microbiota. Gen. Nutr. SI 6, 2011, pp. 275-284.

3. El-Shafei K., Abd El-Gawad M.A.M., Dabiza N., Sharaf O.M., Effat B.A. A mixed culture of Propionibacterium thoenii P-127, Lactobacillus rhamnosus and Lactobacillus plantarum as protective cultures in Kareish cheese. Pol. J. Food Nutr. Sci., vol. 58, 2008, pp. 433-441.

4. Ma C.J., Wu J.M., Tsai H.L., Huang C.W., Lu C.Y., Sun L.C., Shih Y.L., Chen C.W., Chuang J.F., Wu M.H., Wang M.Y., Lin M.T., Wang J.Y. Prospective double-blind randomized study on the efficacy and safety of an n-3 fatty acid enriched intravenous fat emulsion in postsurgical gastric and colorectal cancer patients. Nutr. J., vol. 14, 2015, pp. 9.

5. 7. Sadovoy, V., Omarov, R., Shlykov, S., Shchedrina, T. Assessment compliance of qualitative food characteristics to standard requirements. 15th International Scientific Conference on Engineering for Rural Development, May 25-27, 2016, Jelgava, Latvia, pp. 360-363.

6. Shah N.P. Functional cultures and health benefi ts. Int. Dairy J., vol. 17, 2007, pp. 1262-1277.

7. Vinderola C.G., Reinheimer J.A. Lactic acid starter and probiotic bacteria, a comparative «in vitro» study of probiotic characteristics and biological barrier resistance. Food Res. Int., vol. 36, 2003, pp. 895-904.

8. Hobbie, J. E., Daley R J., Jasper S. Use of Nuclepore filters for counting bacteria by fluorescence microscopy. Appl. Environ. Microbiol. 1977, 33, pp. 1225-1228. 